\title{
Satisfied or Reimbursed: An Innovative Index-Based Mechanism for the Environmental Protection of a Tourist Region
}

\author{
Simone Borghesi ${ }^{1,2}$ \\ 1 Department of International and Political Sciences, University of Siena, 53100 Siena SI, Italy; \\ simone.borghesi@unisi.it \\ 2 Florence School of Regulation-Climate, European University Institute, 50133 Florence FI, Italy
}

Received: 20 June 2020; Accepted: 12 October 2020; Published: 22 October 2020

\begin{abstract}
This article describes and discusses an innovative index-based environmental protection mechanism involving both tourists and local firms of a given region. The public administration offers tourists (non-polluting firms) the possibility of being reimbursed if the environmental quality in the region turns out to be below (above) a given threshold level. Since the two kinds of reimbursements (to visitors and firms) are linked to the same ecological indicator, they will tend to compensate each other, so that the mechanism could be implemented without incurring any cost for the public administration. The article identifies potential difficulties that may arise in its application and proposes corresponding solutions to address them.
\end{abstract}

Keywords: ecological indicators; tourism; non-polluting technologies; threshold levels; financial mechanisms

\section{Introduction}

The need to balance the capacity of sustaining local economic activities with that of attracting tourism is one of the main challenges for many regions. The desire to attract tourists often clashes with that to pursue local production activities, some of which can potentially be environmentally damaging.

This article proposes and describes an innovative financial mechanism that may contribute to solving this problem. Although it has not been implemented in any real context yet, it could be easily applied to any ecological indicator of any developed or developing region that attracts tourism. In the last few years, financial assets have received increasing attention in the economic literature as suitable policy instruments to achieve environmental targets in terms of pollution abatement [1-3]. In particular, several studies have emphasized the increasingly important role that ecological indicators play for the definition of new financial instruments [4-6]. Differently from the existing financial instruments, the present proposal aims at creating an incentive mechanism set by the Public Administration (PA) that involves both local firms and potentially interested tourists, inducing the former to reduce their pollution to achieve a given environmental standard and the latter to actually come and visit the region.

The present paper builds upon Antoci et al. [7,8], who examined the dynamics emerging in an evolutionary game model from the application of a similar mechanism. Differently from those contributions, this paper intends to convey the basic idea to a large audience of non-specialists and to discuss some implementation problems that may arise in practice as well as to propose related solutions.

\section{Theoretical Background: Description of the Proposed Mechanism}

Suppose the local government of a tourist region R carries out two operations. On the one hand, it sells to the tourists an environmental financial option that gives them the possibility of getting a 
reimbursement if the environmental quality in the region turns out to be unsatisfactory (i.e., below a given threshold level). On the other hand, the public administration (PA) offers the firms that adopt an innovative, non-polluting technology the possibility of getting a reimbursement to cover the additional costs imposed by the new technology if the environmental quality turns out to be sufficiently good (i.e., above the threshold level).

The environmental quality of region $R$ could be measured by some independent authority (e.g., a monitoring institution or a pool of scientists and experts who collect environmental data in the region), and the threshold level of the ecological indicator to be met should be determined by the local government so as to safely satisfy the carrying capacity of the ecosystem of the region.

Since the two kinds of reimbursements (to visitors and firms) are linked to the same ecological indicator, they will tend to compensate each other. More precisely, if the environmental quality target is achieved, the entries that the PA gets from selling the financial options to the visitors provide the financial support given to the non-polluting firms. If, on the contrary, the environmental quality target is missed, the entries earned by the PA will finance the reimbursements due to the visitors. In the latter case, one can distinguish two possible alternatives. The first possibility is that the PA simply returns all the money to the tourists and the innovative firms receive no financial aid at all. If this is the case, the PA will have neither entries nor exits, leaving its budget unchanged. As a second alternative, the PA might give the tourists a partial (rather than full) reimbursement and use the difference to finance the few virtuous firms that adopted the non-polluting technology. Differently from the first alternative (in which tourists are fully reimbursed, whereas innovative firms get no financial support), in this second alternative, both tourists and innovative firms would receive a partial reimbursement, thus somehow sharing the risks of their respective choices (experiencing a low environmental quality for the tourists and not achieving the environmental target for the firms). Although the tourists would be no longer "fully protected" from the risk of an unsatisfactory holiday in the region during their stay, they might still be attracted by the possibility of getting a "discount" in the case of low environmental quality. Similarly, although the non-polluting firms might receive a lower financial support if the overall environmental target is missed, the possibility of getting some support (plus the possible early-mover advantages deriving from technological innovation) might contribute to convincing them to lead the way towards the adoption of the new technology.

The fund-raising mechanism proposed here, therefore, could potentially be implemented at no costs for the PA and may become a useful instrument to promote and spread a technological shift across the firms from a polluting technology towards a more environmentally friendly one. In this way, the PA could attract tourists while protecting the local environment without incurring additional costs that burden the local budget.

The environmental protection mechanism described above is completely innovative with respect to the policy instruments used so far. It is based on similar "satisfied or reimbursed"-like mechanisms in which the unsatisfied customer can ask for a refund of the money spent for a given good or service. Such a mechanism, however, has never been applied to environment-related goods.

Some tour operators around the world offer a partial refund to tourists if a naturalistic tour turns out to be unsuccessful. For instance, if one goes whale watching in New Zealand or for a Northern lights spotting excursion in Iceland, some companies guarantee a refund of the ticket if no whales or Northern lights are seen during the tour. That mechanism, however, is unrelated to the firms' economic activity; therefore, it is completely different from the one described here, as it does not create any incentive to local firms to improve their own environmental performance. Other tour operators along the coasts of the Adriatic Sea in Italy have offered tourists refunds of hotel expenditures if the sea quality is severely lowered by algal bloom. In addition to nutrients from intensive agriculture, higher water surface temperature is a major cause of this phenomenon, which depends, therefore, on $\mathrm{CO}_{2}$ emissions all over the world and not just on those locally produced. Hence, differently from the mechanism described here, even that refund mechanism created no direct incentive to local firms to improve their environmental performance. 
Similarly, some beach resorts in Jesolo (in the North of Italy, near Venice) started offering full reimbursement of the amount paid by tourists if it rains. Bathers are asked to pay an extra euro when booking their beach chairs and umbrellas online in order to be eligible for reimbursement. Refunds are granted if the total amount of rain falling during a specific time interval (11:00-17:00) on that day overcomes a pre-established threshold $(3 \mathrm{~mm})$, as measured by the local Environmental Authority. Despite the similarity with the mechanism proposed above, even in this case, the ecological indicator adopted for the reimbursement (rainfall) is exogenous to the local economic system; therefore, it does not generate any link between the firms' environmental behavior and the financial support they may get, which represents the novelty of the present proposal.

The idea proposed above, moreover, extends the application of the deposit-refund system underlying Environmental Bonds (cf. [9-13]) from the potential local polluters to the tourists, thus generating a strong interdependency between the interests of the two sets of agents. Differently from Environmental Bonds, in the present case, the agents do not have to suffer the burden of the proof that they satisfied the required environmental standard. Moreover, the PA does not have to verify the evidence presented by each bond holder, but should only monitor the overall level of the selected ecological indicator, which lowers monitoring costs for the PA.

Finally, the proposed mechanism shares some common features with the index-linked policy performance bonds that have been proposed in the literature (see [14,15]), but it also presents important differences and innovative features with respect to them that can improve the functioning of the system. In particular, index-linked bonds increase the interest payable by the government if the latter fails to achieve its environmental target, whereas in the present case, the government simply returns the money to the tourists in case the target is missed without paying any additional interest. Furthermore, while the funds raised by index-linked bonds would not be hypothecated to green projects, the mechanism proposed above would directly link tourists' entries to firms' investments in clean technologies, thus channeling the funds to green projects and reinforcing the mutual interdependence between the choices of the two sets of agents.

\section{Discussion: Implementation Problems and Possible Solutions}

The financial mechanism proposed here might be applied to several ecological indicators that are used to measure the environmental quality of different geographical areas. In this regard, for instance, the water quality of several coastal areas could provide a particularly interesting case study and a possible prototype for similar applications in other areas. Given the large number of tourists that come every year to visit some well-known resorts (located, for instance, in the Mediterranean area, along the Pacific coast of the US, or in Latin America), the threshold level might be determined-for instance-by the maximum amount of water pollutants discharged in the sea by the local firms that operate in the region. If water pollutants are above the carrying capacity of the ecosystem (i.e., environmental quality is below the threshold), the local PA will reimburse the tourists for the disutility they suffered from the low environmental quality experienced during their holiday in the region. If, on the contrary, the water pollutants discharged by the firms are sufficiently low (i.e., environmental quality is above the threshold), then the PA will not have to reimburse the tourists and can use the entries generated by the financial options to provide financial aid to the firms that adopted the new technology for their effort in reducing pollution, thus supporting the diffusion in the area of innovative environmentally friendly technologies. This example of implementation, however, is far from being exhaustive, since the mechanism proposed above could obviously be applied to any ecological system (river, lake, mountain, etc.) that is the destination of tourism for recreational purposes.

The proposed innovative financial mechanism is obviously not immune of possible implementation problems that need to be addressed, but none of them seems to pose insurmountable difficulties. One crucial aspect to be addressed is how high the threshold level should be. If the local government wants tourists to be attracted by the proposed mechanism, it should set the threshold sufficiently above the minimum legal requirement that ensures a safe environment (e.g. the minimum safe water limits 
to take a bath). This can signal potential tourists the higher ambition level of the local jurisdiction with respect to the past or compared with other jurisdictions. The higher the threshold set by the regulator, the stronger this signal will be both to potential tourists and to local firms involved in the scheme. Obviously, the regulator will have to balance ambition and credibility in setting the threshold: if the threshold is too high, the target might be missed with a possible reputation loss to the tourist destination which is the very opposite of what the mechanism would like to achieve. To avoid this is the case, the regulator would probably be inclined to properly choose a feasible and not overly ambitious target. However, even if the target was eventually missed, the regulator would not necessarily incur a reputation loss as long as tourists were promptly reimbursed as promised. Indeed, a reputation loss will occur only if the regulator does not reimburse tourists even if the target is missed (that is, if (s)he deviates from what originally promised), not if (s)he acts as anticipated.

Another issue related to the threshold level concerns the size of the reimbursement. Tourists would probably not accept a limited refunding (equal to the cost of the financial option) in case of large environmental damages that lead the ecological indicator much below the threshold. To account for this possibility, refunding could grow with the distance of the environmental indicator from the threshold. Tourists could be eventually overcompensated (i.e. the reimbursement being higher than what they originally paid) in case the indicator is much below the threshold. In this case, the regulator might decide to impose an extra tax on the polluting firms to cover the difference between reimbursement due to tourists and their original payment. In other words, the regulator might use the stick of extra taxation on dirty firms beyond the carrot of subsidizing clean firms through tourists' entries, which would create a further strong incentive for firms to adopt clean technologies.

One possible implementation problem concerns the criterion that the PA should adopt to identify the innovative firms that are eligible for financial support. What kind of innovation should we focus on? Product innovation, process innovation, organizational innovation or else? The proposed mechanism leaves room for application to any kind of innovation that substantially lowers the level of the ecological indicator selected by the PA. The choice of the environmental quality indicator and consequently of the most suitable kind of innovation should depend on the specific features of the local ecosystem.

Another problem may concern the criterion that should be adopted to allocate the subsidies to the innovating firms. Thus, for instance, should the PA equally divide among the innovating firms the whole amount of the entries earned by the options sold to the tourists? Or should it determine the reimbursement level attributed to each firm according to some other criterion (such as the emissions reduction intensity)? While this second approach would certainly better distinguish among the innovative firms, it would require much higher monitoring costs, which would bring us back to the problem described above for the Environmental Bonds. A more pragmatic approach, therefore, could be to identify the best-practice technology (BPT) — that is, the one that achieves the highest pollution abatement for a given pollutant-and divide the tourists' entries among all firms that adopt it. Although this solution is certainly simplistic, the BPT adoption criterion does not require almost any additional monitoring cost once the BPT is identified.

One practical issue to be addressed is how the PA would collect the money from the financial options sold to the tourists. As in the case of the Italian beach resorts described above, when booking online a hotel structure tourists could have the option of paying an extra that give them the right to get the money back in case the environmental quality indicator is below the threshold in the region during their holidays. The online payment of this extra would go directly from the tourist's credit card (or current account) into a specifically devoted PA account, which would also simplify the refund procedure in case of poor environmental quality. In alternative, the PA might want all tourists to participate to the proposed mechanism, making it mandatory rather than optional in order to enhance the amount of entries that can be used to financially support the eco-innovating firms. Making the system mandatory would also prevent possible free-riding problems that might arise as long as the agents who do not buy the option (and so don't pay the related extra) can enjoy the same environmental benefits of those who do buy the option and contribute to the functioning of the scheme. To involve all 
tourists in the proposed mechanism and make it mandatory, the PA might use the daily city tax that is applied in many regions by the hotel structures that host tourists. It could be argued that city tax entries are already used to finance other environmental and non-environmental services offered by the town so that using these entries for an additional purpose (financial support to eco-innovating firms) would inevitably reduce the amount at disposal for other services. To avoid that this is the case, the PA might simply raise the city tax by a limited extra amount to be returned in case of unsatisfactory environmental performance of the area. Tourists would probably perceive the city tax as more transparent than it currently is and might reasonably accept a small increase of it since part of the city tax would now be refundable on the basis of a clear and objective criterion.

A further possible problem concerns the frequency of the monitoring activity. This is relevant in evaluating the average environmental quality experienced during the period spent by the tourist in the region. If a tourist spends just a few days in the region, it is likely that no observations on the ecological indicator in these very days will be available by the monitoring institution. If so, how can the PA evaluate whether the environmental standard has been met during those days and thus decide whether the reimbursement is due to the tourist? One obvious solution is to increase the frequency of the observations as much as possible. In some cases, however, this is likely to substantially increase the monitoring costs; in any case, for some pollutants, it may be impossible to have observations every few days. Therefore, a more pragmatic solution could be to take the most recent environmental observation (or, for instance, an average between the last two observations) as a benchmark to evaluate whether the environmental target has been reached and the tourist is eligible for reimbursement. In other cases, instead, we can already rely on daily observations of selected pollutants so that a proper evaluation would be possible even for short time periods spent in the region by the tourist. Many cities, for instance, already provide and publicly display the daily levels of air pollutants such as particulate matter; therefore, in this case, no additional monitoring costs would be needed with respect to the present to apply the proposed financial mechanism in these municipalities to such ecological indicators. Given the high number of cities that report daily measures of these parameters, this shows that the novel idea suggested here could be applied on a large scale and, in some contexts, would be "ready to use" and easy to implement with no additional costs for the local PA.

The possible existence of tourists' moral hazard behaviors is another problem that might, in theory, hinder the correct functioning of the mechanism. Indeed, tourists might potentially have an incentive to pollute so that the ecological indicator falls just below the threshold level and they can get their money back from the PA. For instance, if reimbursement is linked to an ecological indicator measuring the water quality of the sea, they might be tempted to discharge polluting wastes in the sea in order to lower the value of the selected indicator. Although this possibility cannot be totally dismissed a priori, it does not appear very plausible for several reasons: (i) It would obviously damage the tourists themselves, reducing the welfare they can get from the holidays spent in the region, (ii) it would require tourists to be very well informed (and rational), and (iii) it would require a high level of coordination among tourists. The first reason is self-evident: Being self-defeating, the tourists' misbehavior would make no sense unless it lowers environmental quality by just as much as it is needed to be refunded. This leads to the second point: If tourists do not want to suffer a high welfare loss from their misbehavior, they should have perfect information on the existing pollution level and be able to compute the exact amount of pollution that allows them to lower the ecological indicator just below the threshold, which seems very unlikely. Finally, the polluting activity of a single tourist would probably have a limited impact on the environmental quality of the whole region or resort area. Tourists, therefore, should somehow coordinate their (mis)behaviors if they want to lower the environmental quality below the threshold, which seems also very implausible and difficult to do. A single tourist would obviously be able to provoke serious damages on purpose on her/his own (e.g., discharging highly toxic wastes in the water), but this would make a holiday in that resort totally unpleasant and, therefore, meaningless, which leads back to the first point raised above. Indeed, recall that the potential refund would be linked to the average level of the selected ecological indicator 
reported during the holiday. To get her/his money back, therefore, the tourist who voluntarily provokes heavy environmental damages should lower the value of the indicator during her/his holiday and not at the end of it.

Although tourists' misbehavior seems rather unlikely for the reasons explained before, the PA could establish very severe penalties for tourists who are found to pollute so as to eliminate any incentive for moral hazard behaviors. To provide an example, if the tourist is caught in the act of polluting, (s)he could be sentenced to pay compensation to the other tourists. Such compensation could be proportional to how much the tourist's misbehavior contributed to increasing environmental degradation.

An additional obstacle to the implementation of the proposed mechanism may arise if tourists do not trust the environmental data reported by the local monitoring authority. If the latter is not completely independent of the local PA, tourists may reasonably fear that the PA puts pressure on the monitoring authority to alter the data in order to achieve the environmental target, thus subsidizing the local firms rather than reimbursing the tourists. After all, differently from tourists, the local firms and their employees provide an important basin of votes for the local administrators, which may induce moral hazard behaviors. If tourists have even the slightest doubt that the PA may cheat and use this mechanism to finance local firms, they might not come at all, whatever the reported environmental data. This makes the implementation of the proposed mechanism theoretically more difficult in countries that previously experienced scandals and diffuse cases of corruption and briberies, which casts doubts on the independence and credibility of the monitoring authority. One possible way out may be to have an international monitoring agency with little (possibly no) interests in common with the local administrators. Another even more reliable option could be to adopt a global positioning monitoring system with local environmental data reported from satellite observations. Such data are already available for some pollutants and geographic areas, in some cases (e.g., for many European cities) even at the sub-city district level (cf. [16]). Therefore, they could be promptly used for the present mechanism to increase the perceived reliability of the data and eliminate the risk of cheating described above.

Finally, one may wonder what would happen if tourists do not come to visit the region even if they trust the data and the environmental quality target is reached. The capacity of a given resort to attract tourism, in fact, depends not only on its environmental quality, but also on several other factors, such as the average price level in the area (especially as compared to alternative competing resorts), the existing infrastructures to reach the region, the existence of additional non-environmental attractions (e.g., museums, festivals, sport/art events, etc.). If the quality of the non-environmental factors is poor, one cannot exclude that tourists may stop coming even if the environmental target is achieved. If this is the case, the entries deriving from the financial options sold to the tourists and used to support innovating firms could significantly decrease, with a consequent reduction of the firms' incentive to innovate and improve their environmental performance. Even in this case, the PA would not incur any additional cost and would satisfy its balanced budget constraint, since the financial support for innovation would go hand in hand with the tourists' entries. However, the PA could try to extend the incentive-based mechanism designed here to the unattractive sectors of its economy in order to involve them in the effort to attract tourism and keep a high overall life quality standard in the area. For example, one could imagine that the PA uses the entries obtained from the financial options to support those hotels that achieve a given quality standard. Alternatively, the PA might promote an agreement to share the entries obtained from the financial options between non-polluting firms (that are eligible for the financial support) and the hotels that satisfy their customers' expectations. The analysis of this issue, however, goes beyond the scope of this short article, which is meant to foster possible debate on the new mechanism presented here, and is left for future research.

\section{Conclusions}

Ecological indicators have been widely used in several case studies to assess the sustainability of tourism in a given area (see, among the others, [17-20]). To our knowledge, however, such indicators 
have not been used so far to design a potential tourist reimbursement mechanism based on the environmental performance of local firms. To overcome this gap in the literature, the present paper describes an innovative incentive mechanism set by the public administration (PA) that involves both local firms and potentially interested tourists, inducing the former to reduce their pollution to achieve a given environmental standard and the latter to actually come and visit the region. The mechanism proposed here joins the idea of the environmental bond with a "satisfied or reimbursed"-like mechanism in which the unsatisfied customer can ask for a refund of the money spent for a given good or service. By so doing, it can significantly improve upon each of the two instruments taken separately.

To assess whether this theoretical instrument could work in practice, a few implementation problems that might emerge in real-world applications have been discussed, and suitable ways to solve them have been proposed. The potential problems pointed out above would probably not exhaust the number of possible difficulties that may arise when implementing the proposed mechanism. Therefore, it would be important to launch a pilot project to evaluate the actual functioning of the mechanism in practice. Such a project could be applied in different areas/cities and to different kinds of pollutants to have a sufficient number of case studies that allow to make comparisons and draw lessons from the existing applications.

Funding: This research was partially funded by the University of Siena (grant number 2273-2020-MS-PSR2020_001).

Acknowledgments: The author would like to thank four anonymous reviewers for their useful remarks and suggestions. Any remaining errors are the sole responsibility of the author. Financial support received the University of Siena (Piano Sostegno alla Ricerca 2020) is gratefully acknowledged. The author claims that, differently from the mechanism described in the paper, unsatisfied readers will not be entitled to any reimbursement in case the quality of the paper does not meet their expectations.

Conflicts of Interest: The author declares no conflict of interest.

\section{References}

1. Moreno-Bromberg, S.; Taschini, L. Pollution Permits, Strategic Trading and Dynamic Technology Adoption; Grantham Research Institute Working Paper 45; London School of Economics: London, UK, 2011.

2. Chobotová, V. The role of market-based instruments for biodiversity conservation in Central and Eastern Europe. Ecol. Econ. 2013, 95, 41-50. [CrossRef]

3. Chesney, M.; Gheyssens, J.; Taschini, L. Environmental Finance and Investments; Springer: Berlin/Heidelberg, Germany, 2013.

4. Mainelli, M.; Onstwedder, J.; Parker, K.; Fischer, W. Index-linked Carbon Bonds_Gilty Green Government; Z/Yen Group: London, UK, 2009.

5. Kerste, M.; Rosenboom, N.; Sikken, B.J.; Weda, J. Financing Sustainability-Insights for Investors, Corporate Executives, and Policymakers; VU University Press: Amsterdam, The Netherlands, 2011. Available online: http://ssrn.com/abstract=1893373 (accessed on 20 June 2020).

6. Russi, D.; Margue, H.; Oppermann, R.; Keenleyside, C. Result-based agri-environment measures: Market-based instruments, incentives or rewards? The case of Baden-Württemberg. Land Use Policy 2016, 54, 69-77. [CrossRef]

7. Antoci, A.; Borghesi, S.; Russu, P. Environmental protection mechanisms and technological dynamics. Econ. Model. 2012, 29, 840-847. [CrossRef]

8. Antoci, A.; Borghesi, S.; Galeotti, M. Environmental options and technological innovation: An evolutionary game model. J. Evol. Econ. 2013, 23, 247-269. [CrossRef]

9. Perrings, C. Economy and Environment; Cambridge University Press: Cambridge, UK, 1987.

10. Perrings, C. Environmental bonds and environmental research in innovative activities. Ecol. Econ. 1989, 1, 95-110. [CrossRef]

11. Costanza, R.; Perrings, C. A flexible assurance bonding system for improved environmental management. Ecol. Econ. 1990, 2, 57-75. [CrossRef]

12. Ferreira, D.; Suslick, S.; Farley, J.; Costanza, R.; Krivov, S. A decision model for financial assurance instruments in the upstream petroleum sector. Energy Policy 2004, 32, 1173-1184. [CrossRef] 
13. Gerard, D.; Wilson, E.J. Environmental bonds and the problem of long-term carbon sequestration. J. Environ. Manag. 2009, 90, 1097-1105. [CrossRef] [PubMed]

14. Ekins, P.; McDowall, W.; Zenghelis, D. Greening the Recovery. The Report of the UCL Green Economy Policy Commission; University College London: London, UK, 2014.

15. Mainelli, M.; Onstwedder, J.P. Living up to Their Promises (index-linked carbon bonds). In Environmental Finance; Fulton Publishing: Meadville, PA, USA, 2010; p. 17.

16. European Union. Eurostat Regional Yearbook 2020; Publications Office of the European Union: Luxembourg, 2020.

17. Patterson, T.M.; Niccolucci, V.; Bastianoni, S. Beyond "more is better": Ecological footprint accounting for tourism and consumption in Val di Merse, Italy. Ecol. Econ. 2007, 62, 747-756. [CrossRef]

18. Lozano-Oyola, M.; Blancas, F.J.; González, M.; Caballero, R. Sustainable tourism indicators as planning tools in cultural destinations. Ecol. Indic. 2012, 18, 659-675. [CrossRef]

19. Zhang, J.; Ji, M.; Zhang, Y. Tourism sustainability in Tibet-Forward planning using a systems approach. Ecol. Indic. 2015, 56, 218-228. [CrossRef]

20. Cao, Y.; Wang, B.; Zhang, J.; Wang, L.; Pan, Y.; Wang, Q.; Jian, D.; Deng, G. Lake macroinvertebrate assemblages and relationship with natural environment and tourism stress in Jiuzhaigou Natural Reserve, China. Ecol. Indic. 2016, 62, 182-190. [CrossRef]

Publisher's Note: MDPI stays neutral with regard to jurisdictional claims in published maps and institutional affiliations.

(C) 2020 by the author. Licensee MDPI, Basel, Switzerland. This article is an open access article distributed under the terms and conditions of the Creative Commons Attribution (CC BY) license (http://creativecommons.org/licenses/by/4.0/). 